\title{
Introduction to "Historical and Recent Catastrophic Tsunamis in the World: Volume II. Tsunamis from 1755 to 2010"
}

\author{
Kenji Satake, ${ }^{1}$ Alexander B. Rabinovich, ${ }^{2}$ Dale Dominey-Howes, ${ }^{3}$ and José C. Borrero ${ }^{4,5}$
}

\begin{abstract}
Eighteen papers on past and recent destructive tsunamis are included in Volume II of the PAGEOPH topical issue "Historical and Recent Catastrophic Tsunamis in the World." Three papers discuss deep-sea (DART) and coastal tsunami observations, warning systems and risk management in the Pacific Ocean. Four papers examine the 1755 Lisbon, 1964 Alaska, 2003 Algeria, and 2011 Haiti tsunamis. Four more papers, as well as some papers in Volume I, report on various aspects of the 2010 Chile tsunami. Two papers present some results of field survey and modelling investigation of the 2010 Mentawai, Indonesia, tsunami. Three papers report on modelling efforts of tsunami generation by earthquake and landslide, and of tsunami propagation. Finally, two papers discuss hazard assessment using a probabilistic approach.
\end{abstract}

Key words: Tsunami, DART, tsunami records, the 2010 Chile tsunami, the 2010 Mentawai tsunami, modelling, field survey, tsunami mitigation and assessment.

\section{Introduction}

The Tsunami Commission was established within the International Union of Geodesy and Geophysics

1 Earthquake Research Institute, The University of Tokyo, 1-1-1 Yayoi, Bunkyo-ku, Tokyo 113-0032, Japan. E-mail: satake@eri.u-tokyo.ac.jp

2 P.P. Shirshov Institute of Oceanology, Russian Academy of Sciences, 36 Nakhimovsky Pr., Moscow 117997, Russia. E-mail: a.b.rabinovich@gmail.com

3 Australia-Pacific Tsunami Research Centre and Natural Hazards Research Laboratory, School of Biological, Earth and Environmental Sciences, University of New South Wales, Sydney, NSW 2052, Australia. E-mail: dale.dh@unsw.edu.au

4 eCoast Ltd., Box 151, Raglan 3225, New Zealand. E-mail: jose@ecoast.co.nz

5 Department of Civil and Environmental Engineering, University of Southern California, Los Angeles, CA, USA. E-mail: jborrero@usc.edu
(IUGG) following the 1960 Chile Tsunami, generated by the largest ( $M$ 9.5) instrumentally recorded earthquake. The 1960 tsunami propagated throughout the Pacific Ocean affecting areas far from the source. Since then, the Tsunami Commission has held biannual International Tsunami Symposia and published special volumes of selected papers (e.g., SAtAKe et al. 2007, 2011a, b; Cummins et al. 2008, 2009). Tsunami science and research, as well as warning and hazard mitigation systems, have dramatically developed and improved as a result of the catastrophic 2004 Indian Ocean tsunami produced by the Sumatra-Andaman earthquake ( $M$ 9.1), which was the worst tsunami disaster in recorded human history. Several other destructive events occurred between 2005 and 2010, including the 2006 Java, 2009 Samoa, 2010 Chile and 2010 Mentawai tsunamis. The Tohoku (East Japan) tsunami of 11 March 2011 was a tragic continuation of this chain of devastating events.

The 25th International Tsunami Symposium was held from 1 to 4 July 2011. The symposium occurred within the framework of the Joint Association Session JS01 "Advances in Tsunami Science, Warning, and Mitigation", during the 25th General Assembly of the International Union of Geodesy and Geophysics in Melbourne, Australia. There were 65 oral and 30 poster presentations at the symposium. At the business meeting of the Tsunami Commission, it was decided to publish selected papers presented at this symposium, as well as other papers on related topic. Out of 48 originally submitted papers, 39 papers have been accepted and published in two volumes. Volume I contains 21 papers on the 2011 Tohoku, Japan, tsunami, while Volume II contains 18 papers on other tsunamis and tsunamirelated topics. 
2. Tsunami Observation, Warning Systems and Risk Management

In the early 1980s, the United States National Oceanic and Atmospheric Administration Pacific Marine Environmental Laboratory (NOAA/PMEL) established the fundamentals for contemporary openocean tsunami measurements based on deep-sea bottom pressure recorders (BPRs). The decades of technological and scientific advancements that followed led to a robust network that now provides realtime deep-ocean tsunami observations routinely incorporated into operational procedures of tsunami warning centres around the globe (e.g. Tiтov 2009; MofJeld 2009). Deep-ocean Assessment and Reporting of Tsunamis (DART) bottom pressure stations operated by NOAA as well as other internationally-operated tsunameters using similar technology have became a valuable and important research tool for examining the physics and essential properties of propagating tsunami waves. DART and tsunameter records of bottom pressure have begun to be widely used to investigate recent trans-Pacific tsunamis such as the 2009 Samoa, 2010 Chile and 2011 Tohoku events. The respective papers are presented in Volumes I and II of this topical issue (e.g., Fine et al. 2013; Wei et al. 2013; HeIDARZADEH and Satake 2013a; Borrero and Greer 2013; Shevchenko et al. 2013; Fuji and Satake 2013; and RABINOVICH et al. 2013).

From this point of view, the paper by Mungov et al. (2013) is important and timely. The authors provide a 10-year overview of the DART system discussing all aspects of the tsunameter network both operationally and for research purposes. The entire United States network is operated collaboratively by the National Data Buoy Center (NDBC, Stennis, MS), the Pacific Marine Environmental Laboratory (PMEL, Seattle, WA), and the National Geophysical Data Center (NGDC, Boulder, CO), under direction and oversight by the National Weather Service. The NDBC is responsible for all operational network activities and distributes real-time data to the public, PMEL provides the research component in support of forecast modelling and network enhancements, while the NGDC processes all historical data, integrating these and a suite of multi-source observations into their global historical tsunami database, and serves as the permanent archive and distributer of these processed and integrated observations through web-based portals. The role each agency plays in collecting, processing, and disseminating observations of deep-ocean bottom pressure is detailed along with brief descriptions of procedures. Specific examples of challenges and the approach taken to address these are discussed. The newly developed and available tsunami event web pages are briefly described and demonstrated with processed data for both the 11 March 2011 Tohoku and the 12 January 2010 Haiti tsunamis.

Given that tsunamis can be devastating in terms of loss of human lives, the effectiveness of tsunami early warning systems and their associated messages cannot be underestimated - especially in the near to regional field. Lomax and Michelini (2013) explore a method for providing tsunami early warning messages within as little as five to ten minutes after the earthquake. The effort described in this paper builds upon earlier work by these authors (e.g. LomAx et al. 2007; LomAX and MicheLinI 2011) and represents a significant improvement in this approach. These authors note that, at present, the primary seismic discriminant for estimating tsunami potential is the centroid-moment tensor magnitude and that it takes some time to obtain relevant measurements. The time delay presents an obstacle for rapid early warning. LOMAX and MicheLINI (2013) present an alternative approach for estimating earthquake-tsunami potential using simple measurements on $P$-wave seismograms. The advancement described in this study focuses on treatment of several earthquake parameters in real-time. We note that HiRSHORn et al. (2013) in Volume I also examined a method to estimate the moment magnitude from $P$ waves, $M_{\text {wp }}$, that is adopted by the Pacific Tsunami Warning Center. The approach described here warrants further testing and refining by earthquaketsunami experts and tsunami warning centre scientists and clearly has significant potential.

Despite the scientific and technical developments of tsunami research and its warning systems, tsunami disasters continue to kill people and create severe damage, as demonstrated by the recent 2011 Tohoku tsunami in Japan. Dominey-Howes and Goff (2013) discuss the issues and challenges for tsunami risk 
management, with an emphasis on Pacific island countries and territories. Because a risk consists of hazard and vulnerability, they discuss not only tsunami hazards in the Pacific from earthquake, volcanic and landslide sources, but also the vulnerability from tsunamis related to aspects of public policy. Unlike other papers in this volume on scientific aspects of hazards, they discuss the challenges for identifying, assessing and monitoring tsunami risks. They list some good practice cases for international (Pacificwide tsunami practice), national (Disaster Awareness Month) and local (Tsunami-ready community) levels, and lessons learned from the 2011 Tohoku tsunamis. Their recommendations include better understanding of hazards, improvement in disaster risk reduction policies, and information sharing with communities.

\section{Tsunamis in the Atlantic, North Pacific, Mediterranean and Caribbean}

AllgEYer et al. (2013) explore whether a tsunami like that generated in 1755 might reach the Atlantic coastline of France. They do this by combining new numerical modelling with observations of actual tsunami tide gauge records from the 20th century. The known 20th century tsunamis originating in the region of the 1755 event did not leave discernible signals within tide gauge data from the Atlantic coast of France. However, when these authors used nonlinear, shallow water wave simulations, they detected otherwise unnoticed tsunami signals indicating that in principle, tsunamis generated off the coast of Portugal could affect the Atlantic coast of France. They then used this approach to model various 1755 scenarios and examine the potential effects.

Nikolsky et al. (2013) developed a numerical model to describe the wave dynamics in Chenega Cove, Alaska during the historic $M 9.2$ Alaska megathrust earthquake of 27 March 1964. During the earthquake, locally generated waves of unknown origin were identified at the Village of Chenega, located in the western part of Prince William Sound. The anomalous waves appeared shortly after the shaking began and swept away most of the village buildings, while the shaking still continued. The model was constructed for various tsunami generation processes. The model results are compared with eyewitness reports and observed runup and indicate the importance of both vertical and horizontal displacements in the 1964 tsunami generation process.

A significant thrust earthquake ( $M$ 6.8) on 21 May 2003 in northern Algeria was the strongest to hit this region in two decades. It killed more than 1000 people and injured thousands. The earthquake generated a tsunami that was clearly recorded in the Western Mediterranean by a number of instruments. HEIDARZADEH and SATAKE (2013b) made statistical and wavelet analyses of the tsunami using the records from 19 coastal tide gauges. The largest troughto-crest wave height of $196 \mathrm{~cm}$ was recorded at Sant Antoni, Ibiza Island (Balearic Islands, Spain) in the lee of the incoming tsunami wave. Typically, the largest wave at most stations was observed several hours after the first tsunami arrival. Noticeable tsunami waves lasted for more than one day. The spectra of coastal tsunami records were strongly influenced by topographic effects. The wavelet analysis showed that only a peak at around 23 min was commonly observed at different stations and was persistent for sufficiently long time. Other peaks at $14,30,45$, and $60 \mathrm{~min}$ appeared at short durations. The 23-min signal was probably associated with the source fault width, whereas the fault length contributed to the $45 \mathrm{~min}$ signal. Based on these dominant periods, the tsunami source dimensions were estimated as $95 \mathrm{~km} \times 45 \mathrm{~km}$ which is in good agreement with the source parameters obtained from seismological analyses.

On 12 January 2010 an $M 7.0$ earthquake occurred $25 \mathrm{~km}$ west-southwest of Haiti's capital Portau-Prince causing an estimated 316,000 fatalities, thereby exceeding any previous loss of life from a similar size earthquake. This earthquake generated tsunami waves that caused at least three fatalities at Petit Paradis due to a complete lack of tsunami awareness. An international tsunami survey team (ITST) was deployed within weeks of the event and covered the greater Bay of Port-au-Prince and more than $100 \mathrm{~km}$ of Hispaniola's southern coastline. The results of the ITST study are described by FriTz et al. (2013), who measured a maximum tsunami height of $3 \mathrm{~m}$ and made observations of coastal land level changes. 


\section{Chile Tsunami}

The 27 February 2010 Chile tsunami was caused by an $M 8.8$ earthquake, which at that time was the fifth-largest recorded earthquake since the beginning of the 20th century. It caused a locally devastating tsunami with a maximum height of nearly $30 \mathrm{~m}$ and more than 100 casualties. The tsunami then propagated across the Pacific Ocean causing property damage as far away as Russia, Japan, and the USA.

The largest tsunami along the Chilean coast was recorded several hours after the earthquake. This has been interpreted as the effect of edge waves propagating along the continental shelf due to the energy trapping in shallow water. GeIsT (2013) analytically examined the characteristics of edge waves caused by two types of earthquake sources: a crack model with constant stress drop and a stochastic slip model with variable stress drop. The theoretical results, for a fault geometry and coastal topography representative of the Chilean coast, indicate that the edge wave amplitudes from the stochastic slip model are more variable than those from the crack model, suggesting that slip heterogeneity affects edge waves. He also showed that constructive interface of edge waves and other direct waves can significantly amplify the tsunami heights. This paper demonstrates the need to consider later arriving tsunami for hazard assessments.

The contribution from FusI and Satake (2013) provides detailed source models for the 1960 and 2010 tsunamis generated in southern Chile. Their analysis used tsunami waveforms on DART and coastal tide gauges as well as geodetic data quantifying land level changes to constrain slip amounts for these two earthquakes. For the 2010 earthquake their analysis identified two slip asperities along the fault plane: one located near Constitución to the north and another around the Arauco Peninsula to the south. Hydrodynamic modelling of the tsunami showed that the long-lasting waves along the Chilean coast were caused by edge waves, rather than the heterogeneous slip distribution. Their re-analysis of the 1960 tsunami identified a patch of very high slip $(\sim 30 \mathrm{~m})$ near Validivia and suggests a total fault length of $\sim 800 \mathrm{~km}$.

Shevchenko et al. (2013) analyzed the 2010 Chile tsunami, as well as the Samoa tsunami of 29
September 2009, measured along the Russian Far East. For the region of the South Kuril Islands the authors used the data recorded by bottom pressure gauges of the Institute of Marine Geology and Geophysics (IMGG). For the oceanic coast of Paramushir Island (the North Kuril Islands), the Kamchatka Peninsula and Bering Island, the tsunamis were recorded by coastal tide gauges of the Russian Tsunami Warning Service (TWS). The maximum trough-to-crest heights of the Samoa tsunami were approximately $30-40 \mathrm{~cm}$ and were recorded some $3 \mathrm{~h}$ after the first tsunami arrival. The maximum troughto-crest wave heights of the Chile tsunami were $218 \mathrm{~cm}$ at Severo-Kurilsk (Paramushir Island), $187 \mathrm{~cm}$ at Tserkovnaya Bay (Shikotan Island), and $140 \mathrm{~cm}$ at Khodutka Bay (Kamchatka Peninsula) and the time between the first and maximum waves was approximately $4 \mathrm{~h}$. The Samoa tsunami induced highfrequency oscillations: considerable increase in spectral energy was observed at periods of 4 to 20 min. In contrast, the Chile tsunami was found to induce low-frequency oscillations with the dominant periods of 30 to $80 \mathrm{~min}$. A probable reason for these differences is the different extensions of the tsunami source areas (the Chilean source was much larger than the Samoan source) and the different energy radiation directions from the sources. Local topographic resonant effects were the main reason of well-expressed peaks in the observed spectra at different sites.

RABINOVICH et al. (2013) examined instrumental data associated with the 2010 Chile tsunami recorded on the Pacific coast of Canada and the northwestern coast of the United States. These were compared with similar records of the 1960 Chile tsunami. Whilst the 1960 tsunami was recorded only on coastal tide gauges, the 2010 tsunami was also recorded by offshore bottom pressure gauges of the NEPTUNECanada cabled observatory array and nearby DART stations. The comparison of coastal records in British Columbia indicates that the amplitude of the 2010 tsunami was about $30 \%$ of the 1960 tsunami and arrived about $1 \mathrm{~h}$ earlier. The high-quality data from the 2010 tsunami event allowed the authors to perform cross-spectral and wavelet analysis revealing the coastal shoaling process and characteristics of the maximum wave that arrived several hours after the initial arrival. 
Several papers in Volume I also report the 2010 Chile tsunami comparing this tsunami with the 2011 Tohoku event. Yoshir et al. (2013) report their geochemical analysis of soils after the 2010 Chile tsunami on Talcahuano coast. WILson et al. (2013) report the effects of the 2010 tsunami on the US west coast including resonant oscillations and associated strong currents within harbours. In California, the 2010 event generated a maximum tsunami amplitude of $1.2 \mathrm{~m}$ at Pismo Beach and caused more than $\$ 3$ million damage to boats and docks in nearly a dozen harbours. The response in Californian harbours was also examined by Xing et al. (2013). Reymond et al. (2013) describe the effects of the 2010 tsunami in French Polynesia, as well as the timeline of the warning procedures, the information flow in the warning centre and to the local authorities. BORRERO and GREeR (2013) analyzed the tsunami waveforms recorded at coastal tide gauges in New Zealand and California, as well as DART data, to explore far-field characteristics of the 2010 Chile tsunami.

\section{Mentawai, Indonesia Tsunami}

The earthquake on 25 October 2010 off the Mentawai Islands, Indonesia, was a "tsunami earthquake" which generated a much larger tsunami than would be expected based on the seismic magnitude or the severity of the ground shaking (e.g., KanAmORI 1972) and ultimately resulted in more than 500 casualties. SATAKE et al. (2013) report on their field survey of the tsunami effects in which they measured tsunami heights of mostly 4-7 m along with inundation of more than $300 \mathrm{~m}$ on the Pagai Islands. They round out the study by providing comprehensive hydrodynamic modelling results. For this, they derived a source model through the inversion of tsunami waveform records from an offshore buoy, a DART gauge and coastal tide gauges. Their inversion suggests that the largest slip on the fault was approximately $6 \mathrm{~m}$ near the trench axis, a feature similar to other tsunami earthquakes. Their hydrodynamic modelling results also highlight the difficulty in producing detailed inundation assessments for regions lacking good quality bathymetry and topography data.
The 2010 Mentawai tsunami is also the focus of Putra et al. (2013). In this paper the sedimentological characteristics of deposits left by the tsunami are described and quantified. This paper is important in that the depositional environment is dominated by carbonate sediments and is an important contribution to the literature, since most published tsunami deposit work focuses primarily on silica or heavy-mineral prevailed sediments. In contrast to mineral-dominated deposits, the density of carbonate grains as a function of size may be an important consideration when carbonatedominated deposits are used to interpret hydraulic condition that created a particular tsunami deposit. The authors also employ a foraminiferal analysis to illustrate that the likely source region for the deposit material is from water depths of less than $50 \mathrm{~m}$.

\section{Tsunami Modelling and Hazard Assessment}

Numerical tsunami simulations have become a standard method for the forecasting or hindcasting of the tsunami generation and propagation processes. The tsunami arrival times and amplitudes can be estimated from the simulation, or the observed tsunami waveforms can be compared to improve the source modelling. Allen and GreEnslade (2013) introduce indices to objectively compare the simulated and observed tsunami waveforms. The eight indices they examined include the comparison of maximum amplitudes, the correlation coefficients, normalized root-mean-square errors, the Index of Agreement and the transformed Mielke Index. They examined these indices for simulated waveforms and those in the T2 scenario database currently used in Australia, by assuming errors in the earthquake magnitudes, the location of earthquakes, and both. While they tentatively recommend that the Index of Agreement be used for tsunami forecast purposes, the performance of this parameter is sensitive to various conditions such as the amplitude or the duration of the waveforms. The methodology proposed here can be, and needs to be, tested for comparisons between the simulated and observed tsunami waveforms in the future studies.

Power et al. (2013) and LANE et al. (2013) presented a two-part study estimating tsunami risk for the Auckland region of New Zealand. The authors 
developed a probabilistic model for the tsunami hazard posed to this region from the Kermadec Trench and the southern New Hebrides Trench subduction zones. An innovative feature of this model, in the authors' opinion, is the systematic analysis of uncertainty regarding the magnitude-frequency distribution of earthquakes in the source regions. The methodology is first used to estimate the tsunami hazard at the coastline; and then used to produce a set of scenarios that can be applied to produce probabilistic maps of tsunami inundation for the study region. Part I of this study (Power et al. 2013) is mainly devoted to the methodological aspects of the problem and to simulation of tsunami propagation in the open ocean, while Part II (Lane et al. 2013) focuses on coastal inundation and the production of the respective hazard maps. The 2500 year return period ("Average Recurrence Interval") of regional source tsunami hazard was found to be dominant for the densely populated east coast of Auckland and the sparsely populated west coast. Incorporating tidal effects into predictions of inundation gives a more accurate hazard assessment.

Nosov et al. (2013) discussed horizontal motions of water in the tsunami generation process. While the vertical water motion, or water height, is mainly considered in tsunami studies, tsunamis are shallowwater waves in which the water particle motion is predominantly in a horizontal direction. The authors proposed to look at "residual horizontal motion of water", which is a displacement of water particles from their initial positions. In addition, to show the theoretical framework, they present the results of numerical simulation for the 2011 Tohoku tsunami. They show that the horizontal displacement ranges from tens to hundreds of meters, and discuss ways to detect them for the purposes of tsunami warning.

Didenkulova and Pelinovsky (2013) present analytical studies of landslide-generated tsunami. They show that simple one-dimensional equations can be derived from two-dimensional shallow-water theory with simple cross sections (U-shaped and $\mathrm{V}$-shaped bays or rectangular channels), and show the variation of amplitude along a bay or channel. If the landslide speed matches with the tsunami phase speed, the tsunami amplitude will amplify due to the resonance effect. While a simple resonant theory for uniform depth would predict an infinite amplitude, the more realistic theory with variable bottom topography and variable with distance landslide volume show finite tsunami amplitudes. The analytical solutions of the authors may be compared with numerical studies or physical experiments for landslide-generated tsunamis.

\section{Acknowledgments}

We, the Guest Editors, would like to thank Drs. Brian Mitchell and Renata Dmowska, the Editors-in-Chief of PAGEOPH, for arranging and encouraging us to organize the topical volumes. We also thank Ms. Nivashini Mathivanan and Mr. Naresh Santhanam at Journals Editorial Office of Springer for their timely editorial assistance. Finally, we would like to thank all the authors and reviewers who contributed to these topical volumes.

\section{REFERENCES}

Allen, S.C.R., and Greenslade, D.J.M. (2013), Indices for the objective assessment of tsunami forecast models. Pure Appl. Geophys. (this issue); doi:10.1007/s00024-012-0522-4.

Allgeyer, S., Daubord, C., Hébert, H., Loevenbruck, A., SchinDELÉ, F., and Madariaga R. (2013), Could a 1755-like tsunami reach the French Atlantic coastline? Constraints from twentieth century observations and numerical modeling. Pure Appl. Geophys. (this issue); doi:10.1007/s00024-012-0513-5.

Borrero, J.C., and Greer, S.D. (2013), Comparison of the 2010 Chile and 2011 Japan tsunamis in the far field. Pure Appl. Geophys.; doi:10.1007/s00024-012-0559-4.

Cummins, P.R., Kong, L.S.L., and Satake, K. (2008), Tsunami Science Four Years after the 2004 Indian Ocean Tsunami. Part I: Modelling and Hazard Assessment, Pure Appl. Geophys. 165 (11/12), Topical Issue.

Cummins, P.R., Kong, L.S.L., and Satake, K. (2009), Tsunami Science Four Years after the 2004 Indian Ocean Tsunami. Part II: Observation and Data Analysis, Pure Appl. Geophys. 166 (1/2), Topical Issue.

Didenkulova, I., and Pelinovsky, E. (2013), Analytical solutions for tsunami waves generated by submarine landslides in narrow bays and channels. Pure Appl. Geophys. (this issue); doi: 10.1007/s00024-012-0510-8.

Dominey-Howes, D., and GofF, J. (2013), Tsunami risk management in Pacific island countries and territories (PICTs): Some issues, challenges and ways forward. Pure Appl. Geophys. (this issue); doi:10.1007/s00024-012-0490-8.

Fine, I.V., Kulikov, E.A., and Cherniawsky, J.Y. (2013), Japan's 2011 tsunami: Characteristics of wave propagation from observations and numerical modeling, Pure Appl. Geophys.; doi: 10.1007/s00024-012-0555-8. 
Fritz, H.M., Hillaire, J.V., Molière, E., Wei, Y., and Mohammed F. (2013), Twin tsunamis triggered by the 12 January 2010 Haiti earthquake. Pure Appl. Geophys. (this issue); doi:10.1007/ s00024-012-0479-3.

FujII, Y., and Satake, K. (2013), Slip distribution and seismic moment of the 2010 and 1960 Chilean earthquakes inferred from tsunami waveforms and coastal geodetic data, Pure Appl. Geophys. (this issue); doi:10.1007/s00024-012-0524-2.

GeIst, E.L. (2013), Near-field tsunami edge waves and complex earthquake rupture. Pure Appl. Geophys. (this issue); doi: 10.1007/s00024-012-0491-7.

Heidarzadeh, M., and Satake, K. (2013a), Waveform and spectral analyses of the 2011 Japan tsunami records on tide gauge and DART stations across the Pacific Ocean. Pure Appl. Geophys.; doi:10.1007/s00024-012-0558-5.

Heidarzadeh, M., and Satake, K. (2013b), The 21 May 2003 tsunami in the Western Mediterranean Sea: Statistical and wavelet analyses. Pure Appl. Geophys. (this issue); doi:10.1007/s00024012-0509-1.

Hirshorn, B., Weinstein, S., and Tsuboi, S. (2013), On the application of $M_{w p}$ in the near field and the March 11, 2011 Tohoku earthquake. Pure Appl. Geophys.; doi:10.1007/s00024-012-0495-3.

Kanamori, H. (1972), Mechanism of tsunami earthquakes, Phys. Earth Planet. Inter., 6, 346-359.

Lane, E. M., Gillibrand, P.A., Wang, X., and Power, W. (2013), A probabilistic tsunami hazard study of the Auckland region, Part II: Inundation modelling and hazard assessment. Pure Appl. Geophys. (this issue); doi:10.1007/s00024-012-0538-9.

Lomax, A., Michelini, A., and Piatanesi, A. (2007), An energyduration procedure for rapid determination of earthquake magnitude and tsunamigenic potential, Geophys. J. Int., 170, 1195-1209; doi:10.1111/j.1365-246X.2007.03469.x.

Lomax, A., and Michelin, A. (2011), Tsunami early warning using earthquake rupture duration and P-wave dominant period: the importance of length and depth of faulting, Geophys. J. Int., 185, 283-291; doi:10.1111/j.1365-246X.2010.04916.x.

Lomax, A., and Michelini A. (2013), Tsunami early warning within five minutes. Pure Appl. Geophys. (this issue); doi:10.1007/ s00024-012-0512-6.

Mofjeld, H.O. (2009), Tsunami measurements, In: The Sea, Vol.15, Tsunamis, (Eds. A. Robinson and E. Bernard), Harvard University Press, Cambridge, USA, pp. 201-235.

Mungov, G., EblÉ, M., and BouchaRd, R. (2013) DART tsunameter retrospective and real-time data: A reflection on 10 years of processing in support of tsunami research and operations. Pure Appl. Geophys. (this issue); doi:10.1007/s00024-012-0477-5.

Nicolsky, D.J., Suleimani, E.N., and Hansen, R.A. (2013), Note on the 1964 Alaska tsunami generation by horizontal displacements of ocean bottom. Numerical modeling of the runup in Chenega Cove, Alaska. Pure Appl. Geophys. (this issue); doi:10.1007/ s00024-012-0483-7.

Nosov M.A., Moshenceva, A.V., and Kolesov S.V. (2013), Horizontal motions of water in the vicinity of a tsunami source. Pure Appl. Geophys. (this issue); doi:10.1007/s00024-012-0605-2.

Power, W., Wang, X., Lane, E., and Gillibrand P. (2013), A probabilistic tsunami hazard study of the Auckland region, Part
I: Propagation, modelling and tsunami hazard assessment at the shoreline. Pure Appl. Geophys. (this issue); doi:10.1007/s00024012-0543-z.

Putra, P.S., Nishimura, Y., and Yulianto, E. (2013), Sedimentary features of tsunami deposits in carbonate-dominated beach environments: A case study from the 25 October 2010 Mentawai tsunami. Pure Appl. Geophys. (this issue); doi:10.1007/s00024012-0539-8.

Rabinovich, A.B., Thomson, R.E., and Fine, I.V. (2013). The 2010 Chilean tsunami off the west coast of Canada and the northwest coast of the United States. Pure Appl. Geophys (this issue); doi: 10.1007/s00024-012-0541-1.

Reymond, D., Hyvernaud, O., and OKal, E.A. (2013), The 2010 and 2011 tsunamis in French Polynesia: Operational aspects and field surveys. Pure Appl. Geophys.; doi:10.1007/s00024012-0485-5.

SataKe, K., OKal, E.A., and Borrero, J.C. (2007), Tsunami and its hazards in the Indian and Pacific Oceans, Pure Appl. Geophys., 164(2-3), Topical Issue.

Satake K., Rabinovich, A.B., KânoĞLu, U., and Tinti, S. (2011a), Tsunamis in the World Ocean: Past, Present, and Future. Volume I, Pure Appl. Geophys., 168 (6-7), Topical Issue.

Satake K., Rabinovich, A.B., KÂnoĞLu, U., and Tinti, S. (2011b), Tsunamis in the World Ocean: Past, Present, and Future. Volume II, Pure Appl. Geophys., 168 (11), Topical Issue.

Satake, K., Nishimura, Y., Putra, P.S., Gusman, A.R., Sunendar, H., Fuji, Y., Tanioka, Y., Latief, H., and Yulianto, E. (2013), Tsunami source of the 2010 Mentawai, Indonesia earthquake inferred from tsunami field survey and waveform modeling. Pure Appl. Geophys. (this issue); doi:10.1007/s00024-012-0536-y.

Shevchenko, G., Ivelskaya, T., Loskutov, A., and Shishrin, A. (2013), The 2009 Samoan and 2010 Chilean tsunamis recorded on the Pacific coast of Russia. Pure Appl. Geophys. (this issue); doi:10.1007/s00024-012-0562-9.

Titov, V.V. (2009), Tsunami forecasting, In: The Sea, Vol.15, Tsunamis, (Eds. A. Robinson and E. Bernard), Harvard University Press, Cambridge, USA, pp. 371-400.

Wei, Y., Chamberlin, C., Titov, V.V., Tang, L., and Bernard, E.N. (2013), Modeling of the 2011 Japan tsunami: Lessons for near-field forecast. Pure Appl. Geophys.; doi:10.1007/s00024012-0519-z.

Wilson, R.I., Admire, A.R., Borrero, J.C., Dengler, L.A., LegG, M.R., Lynett, P., McCrink, T.P., Miller, K.M., Ritchie, A., Sterling, K., and Whitmore, P.M. (2013), Observations and impacts from the 2010 Chilean and 2011 Japanese tsunamis in California (USA). Pure Appl. Geophys.; doi:10.1007/s00024012-0527-z.

Xing, X., Kou, Z., Huang, Z., and Lee, J.-J. (2013), Frequency domain response at Pacific coast harbors to major tsunamis of 2005-2011. Pure Appl. Geophys.; doi:10.1007/s00024-0120526-0.

YoshiI, T., Imamura, M., Matsuyama, M., Koshimura, S., MatsUOKa, M., Mas, E., and Jimenez, C. (2013), Salinity in soils and tsunami deposits in areas affected by the 2010 Chile and 2011 Japan tsunamis. Pure Appl. Geophys.; doi:10.1007/s00024012-0530-4. 